\title{
Airborne Particulate Matter and Meteorological Interactions during the Haze Period in Malaysia
}

\author{
Carolyn Payus, Noraini Abdullah, and Norela Sulaiman
}

\begin{abstract}
Haze has become a major concern as it has highly significant impacts over Malaysia by several occurrences of haze episodes throughout the country. During the haze periods, airborne particulate matter $\left(\mathrm{PM}_{10}\right)$ was found as the major pollutant while the other air quality parameters remained within the permissible healthy standards. Haze arise by fires from land clearing in Indonesia that builds up during the dry season affecting tourism, transportation, biodiversity, and contributing to health problems across the region. The variations of the $\mathbf{P M}_{10}$ concentrations are due to various atmospheric processes of emissions, dilutions and accumulations that are affected by meteorological conditions. In this study, an analysis of haze status will be performed using $\mathbf{P M}_{10}$ values from two commercial urban and industrial areas, which involved Kajang and Shah Alam, and one station that was located outside the city, which is in Kota Bahru, Kelantan, that was selected as a rural station for comparison. The aim of this study is to determine the correlation of $\mathbf{P M}_{10}$ concentrations with the meteorological factors (namely on temperature, wind speed and ultraviolet intensity) at different monitoring stations (at different type of land use). Twelve (12) multiple regression models with interactions for each station were developed from data sets of 90; the best model was used to forecast the upcoming haze weather.
\end{abstract}

Index Terms-Haze, airborne particulate matter $\left(\mathbf{P M}_{10}\right)$, multiple regression models with interactions, meteorological factors.

\section{INTRODUCTION}

In April 2009, open burning of land and forest in Kalimantan and Sumatra, in Indonesia caused a great haze phenomenon which spread over the larger parts of South East Asia. Malaysia was affected really badly and the haze hits its peak on 24 April, 2009 when the Air Pollution Index has reached levels higher than 300. During that time, a state of emergency was announced. Given the hazardous air quality, schools were closed to keep the children from exposed with the dangerous air pollutants especially from the outdoors. It is reported from previous study that physical and mental health problems are normally the result of excessive exposure to the haze [1]. As in [2], [3] have showed how the impact of haze from forest fires has affected the human lung and respiratory system in Indonesia and Japan, especially to the children. Research also indicates that air pollution has negative effects on human emotions and behaviors [4], [5]. From these

The manuscript received March 14, 2013; revised May 6, 2013.

Carolyn Payus and Noraini Abdullah are with School of Science \& Technology, Universiti Malaysia Sabah (UMS), 88999 Kota Kinabalu, Malaysia (e-mail: cpayus@ gmail.com; norainiabdullah.ums@gmail.com).

Norela Sulaiman is with School of Environmental and Natural Resources Science, Universiti Kebangsaan Malaysia (UKM), 46300 Bangi, Selangor, Malaysia (e-mail: norelaganun@gmail). previous researches, it seems to indicate that the haze can caused greatly on physical and mental health problems, as well as cancer sickness [6], and pre-term delivery [7].

According to the Malaysia Department of Environment [8], haze is define as the weather phenomenon that leads to an atmospheric visibility of less than $10 \mathrm{~km}$ due to the amount of suspended solid or liquid particles, smoke and vapor in the atmosphere. In Malaysia, it has experienced several haze periods since early 1980s in which the airborne particulate matter $\left(\mathrm{PM}_{10}\right)$ was found to be the major pollutants, while other parameters remained within the permissible limit [9]-[11]. Haze formation is strongly influenced by meteorological conditions [12]-[14]. Meteorological factors have a complex interaction on the various processes such as emission, transport and chemical transformation, as well as wet and dry depositions [15], [16]. The spatial and temporal behaviors of wind fields are characterized by the high coarseness of the surface and differences in thermal conditions [17], [18]. To get a better overview of the haze pollution in Southeast Asia, particularly in Malaysia, this study investigate the importance of meteorology factors in determining the haze pollution, which in this case using the $\mathrm{PM}_{10}$ concentrations as the factor. The $\mathrm{PM}_{10}$ was chosen in this study because it has been identified as an important atmospheric pollutant in major cities in Malaysia, and also due to the fact that during the haze phenomena, haze contributes a highly amount of $\mathrm{PM}_{10}$ in the atmosphere. The study focuses on the impact of meteorological parameters, namely temperature, ultraviolet intensity and the wind speed, on $\mathrm{PM}_{10}$ variability at the urban and rural area during the haze period in Malaysia.

\section{MATERIALS AND METHODS}

\section{A. Study Area}

There are three air monitoring stations used in this study; which are the Kajang (S1), Shah Alam (S2) and for comparison Kota Bahru - Kelantan (S3) was selected, and all stations are on Peninsular Malaysia (West Malaysia). The Kajang (S1) and Shah Alam (S2) are located in the Klang Valley area, on the west coast of Peninsular Malaysia. These stations experience weather with consistent temperatures throughout the year with an average high temperature of $33^{\circ} \mathrm{C}$ and an average low temperature of $27^{\circ} \mathrm{C}$. The cities are warmest in the month of March, and experiences heavy rains and showers during the month of November as the northeast monsoon moves in from October to March. The two stations are expected to be highly polluted due to industrialization; rapid development and economic growth, accompanied by a 
drastic population expansion. The data from these two stations were compared with the data recorded at Kota Bahru-Kelantan (S3), as a baseline station.

\section{B. Data Collection}

The air quality data for this study were obtained from the Air Quality Division of the Department of Environment, from the Malaysian Ministry of Natural Resource and the Environment. The air pollutant parameter used in this study was the airborne particulate matter $\left(\mathrm{PM}_{10}\right) \cdot \mathrm{PM}_{10}$ was chosen in this study, due to the fact that during the haze phenomena, haze contributes a highly amount of $\mathrm{PM}_{10}$ in the atmosphere. It was also found as the major pollutant, while the other air quality parameters remained within the permissible healthy standards. The meteorological parameters involved in this study were ambient temperature, ultraviolet intensity and wind speed. The data were collected over a period of 1 year through a continuous air quality monitoring during the haze phenomena. In this analysis, the hourly concentrations for meteorological conditions and $\mathrm{PM}_{10}$ were used. Due to the haze peak and the Air Pollution Index has reached levels higher than 300, air quality and meteorological data for year 2009 was used for the study.

\section{Statistical Analyses}

Multiple regression (MR) models with interactions: Multiple Regression analysis, a form of general linear modeling [19] is a statistical technique that can be used to analyze the relationship between a single dependent (criterion) variable, $Y$ and several independent (predictor) variables, $x$ 's. A random response $Y$ relating to a set of independent variables $x_{1}, x_{2}, \ldots, x_{k}$ based on the multiple regression model is as shown in equation (1) below [20]:

$$
Y=\gamma+\beta_{1} x_{1}+\beta_{2} x_{2}+\ldots+\beta_{k} x_{k}+\varepsilon
$$

where; $\gamma, \beta_{1}, \ldots, \beta_{k}$ are unknown parameters and $\varepsilon$ is an error term factor.

The description of these variables involved can be seen in Table I.

TABLE I: DESCRIPTION OF VARIABLES INVOLVED IN THE MODEL BUILDING

\begin{tabular}{cc}
\hline Variable & Description \\
\hline $\mathrm{Y}$ & $\mathrm{PM}_{10}$ \\
$\mathrm{X}_{1}$ & Temperature \\
$\mathrm{X}_{2}$ & $\mathrm{UV}$ \\
$\mathrm{X}_{3}$ & Wind Speed \\
\hline
\end{tabular}

The objective of regression analysis is to predict a single Dependent Variable (DV) from the knowledge of one or more Independent Variables $\left(\mathrm{IV}_{\mathrm{S}}\right)$. Interaction effects represent the combined effects of variables on the criterion or dependent measure. When an interaction effect is present, the impact of one variable depends on the level of the other variable. Part of the power of Multiple Regression (MR) is the ability to estimate and test interaction effects when the predictor variables are either categorical or continuous. As in [21] had mention, the idea that multiple effects should be studied in research rather than the isolated effects of single variables is one of the important contributions in Multiple

\section{Regression (MR).}

Procedures in Getting the Best Model: According to model building by [22], twelve possible models can be obtained from three independent variables as stated before. The summary of all possible models is shown in Table II. The table shows seven individual models are without interactions while the four models are up to first order and one with a second order interaction.

TABLE II: SUMMARY OF ALL POSSIBLE MODELS

\begin{tabular}{ccccc}
\hline \multirow{2}{*}{$\begin{array}{c}\text { Number of } \\
\text { Variables }\end{array}$} & Individual & \multicolumn{3}{c}{ Interactions } \\
\cline { 3 - 5 } & 3 & First Order & Second Order & Total \\
\hline 1 & 3 & 3 & & 3 \\
2 & 1 & 1 & 1 & 6 \\
3 & 7 & 4 & 1 & 3 \\
Total & & & & 12 \\
\hline
\end{tabular}

\section{RESULTS AND DisCUSSIONS}

Modelling results: The Multiple Regression (MR) models are developed based on the model building phases using the datasets for each station. The selected models obtained by the multicollinearity and coefficient tests. The existence of multicollinearity can be identified if correlation coefficients $\geq 0.95(|r| \geq 0.95)$. Pearson correlation analysis verifies that there is an existence of multicollinearity between the independent variables in the parent model M11, as shown in Table III.

TABLE III: MODEL M11 WITH MULTICOLLINEARITY EFFECTS

\begin{tabular}{|l|r|r|r|r|r|r|r|}
\hline & $Y$ & $X 1$ & \multicolumn{1}{c|}{$X 2$} & \multicolumn{1}{c|}{$X 3$} & $X 12$ & $X 13$ & $X 23$ \\
\hline $\mathrm{Y}$ & 1 & & & & & & \\
\hline $\mathrm{X} 1$ & 0.176634 & 1 & & & & & \\
\hline $\mathrm{X} 2$ & -0.18366 & 0.551325 & 1 & & & & \\
\hline $\mathrm{X} 3$ & -0.12407 & 0.472772 & 0.58147 & 1 & & & \\
\hline $\mathrm{X} 12$ & -0.15807 & 0.613068 & 0.996184 & 0.59445 & 1 & & \\
\hline $\mathrm{X} 13$ & -0.07321 & 0.614645 & 0.62509 & 0.984976 & 0.649663 & 1 & \\
\hline $\mathrm{X} 23$ & -0.22407 & 0.574743 & 0.941743 & 0.796531 & 0.945838 & 0.82404 & 1 \\
\hline
\end{tabular}

Table IV shows that, after two process of removal for the least effect on the dependent variable, now there are no more multicollinearity variables in the model M11.2, where the correlation coefficients are all $\leq 0.95$.

TABLE IV: MODEL M11.2 WITH NO MORE MULTICOLLINEARITY SOURCE

\begin{tabular}{|l|r|r|r|r|r|}
\hline & $Y$ & $X 1$ & $X 12$ & $X 13$ & $X 23$ \\
\hline $\mathrm{Y}$ & 1 & & & & \\
\hline $\mathrm{X} 1$ & 0.176634 & 1 & & & \\
\hline $\mathrm{X} 12$ & -0.15807 & 0.613068 & 1 & & \\
\hline $\mathrm{X} 13$ & -0.07321 & 0.614645 & 0.649663 & & \\
\hline $\mathrm{X} 23$ & -0.22407 & 0.574743 & 0.945838 & 0.82404 & 1 \\
\hline
\end{tabular}

Model M11.2 then becomes M11.2.1 after the removal of the insignificant variable of X1. Model M11.2.1 hence signified M11 as the parent model, two multicollinearity source variables being removed and one insignificant variable eliminated. 
TABLE V: COEFFICIENT TEST ON MODEL M11.2.1

\begin{tabular}{|l|r|r|r|r|}
\hline & Coefficients & Standard Error & \multicolumn{1}{c|}{ Stat } & \multicolumn{1}{c|}{-value } \\
\hline Intercept & -18.0713 & 13.86192 & -1.30366 & 0.195828 \\
\hline X12 & 0.01916 & 0.004096 & 4.677528 & $1.07 \mathrm{E}-05$ \\
\hline X13 & 0.95547 & 0.198368 & 4.816641 & $6.21 \mathrm{E}-06$ \\
\hline X23 & -0.19387 & 0.035836 & -5.40998 & $5.59 \mathrm{E}-07$ \\
\hline
\end{tabular}

Next, all the twelve possible models have to undergo the model-building phases in [22]. Table VI shows the corresponding selection criteria values for each of the seven selected models obtained from station Kajang (S1) after the multicollinearity and coefficient tests. It can be seen that model M11.2.1 has the majority of the least values of the eight selection criteria (8SC).

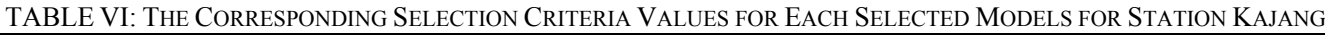

\begin{tabular}{|c|c|c|c|c|c|c|c|c|c|c|c|}
\hline MODEL & $\mathrm{K}+1$ & $\mathrm{~N}$ & SSE & AIC & FPE & GCV & HQ & RICE & SCHWARZ & SGMASQ & SHIBATA \\
\hline M4.0.0 & 3 & $\begin{array}{l}9 \\
0\end{array}$ & 11012.23 & 130.7934 & 130.7966 & 130.9421 & 135.263 & 131.098 & 132.028 & 126.5774 & 130.5153 \\
\hline M5.0.0 & 3 & $\begin{array}{l}9 \\
0 \\
\end{array}$ & 11758.79 & 139.6603 & 139.6638 & 139.8191 & 144.433 & 139.9856 & 140.3699 & 135.1585 & 139.3634 \\
\hline M8.1.0 & 3 & $\begin{array}{l}9 \\
0 \\
\end{array}$ & 11009.76 & 130.7641 & 130.7673 & 130.9127 & 135.2327 & 131.0686 & 132.0004 & 126.549 & 130.4861 \\
\hline M9.1.0 & 3 & $\begin{array}{l}9 \\
0\end{array}$ & 11789.47 & 140.0247 & 140.0281 & 140.1839 & 144.8098 & 140.3508 & 140.7127 & 135.5111 & 139.727 \\
\hline M10.0.0 & 3 & $\begin{array}{l}9 \\
0\end{array}$ & 11120.54 & 132.0798 & 132.0831 & 132.23 & 136.5934 & 132.3874 & 133.2384 & 127.8224 & 131.799 \\
\hline M11.2.1 & 4 & $\begin{array}{l}9 \\
0\end{array}$ & 9351.375 & 113.563 & 113.5697 & 113.7944 & 118.7667 & 114.0412 & 113.4618 & 108.7369 & 113.1401 \\
\hline M12.3.0 & 5 & $\begin{array}{l}9 \\
0\end{array}$ & 9776.357 & 121.3918 & 121.4057 & 121.7816 & 128.3842 & 122.2045 & 118.2137 & 115.016 & 120.6958 \\
\hline \multicolumn{3}{|c|}{ MIN VALUE } & 9351.375 & 113.563 & 113.5697 & 113.7944 & 118.7667 & 114.0412 & 113.4618 & 108.7369 & 113.1401 \\
\hline
\end{tabular}

The best model M11.2.1 is then validated based on the residual analysis using the randomness and normality tests. Fig. 1 and Fig. 2 show the scatter plot of the randomness test and normality plot of the normality test of the best model M11.2.1. It can be seen that the plots have met the assumptions of the regression analysis. All the regression models for all the stations are developed by executing the model building phases.

Table VII below shows the comparison of the regression models obtained from the stations in Kajang (S1), Shah Alam (S2) and Kota Bharu (S3). There are seven selected models from stations Kajang (S1) and Shah Alam (S2) while only one selected model remained for Kota Bharu (S3). The best model with least SSE for station Kajang (S1) is M11.2.1; for station Shah Alam (S2) is M5.0.0; and for station Kota Bharu (S3) is M2.0.0.

Scatterplot

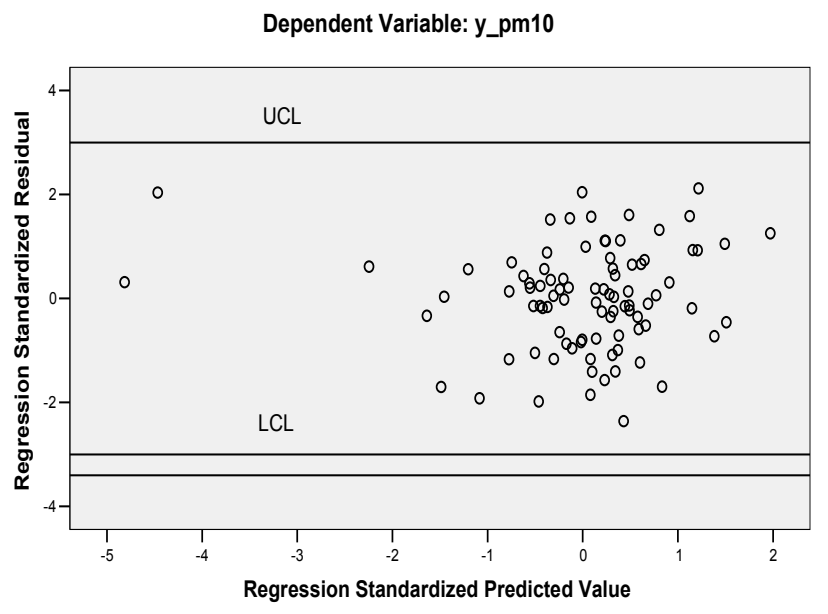

Fig. 1. Randomness test
Histogram

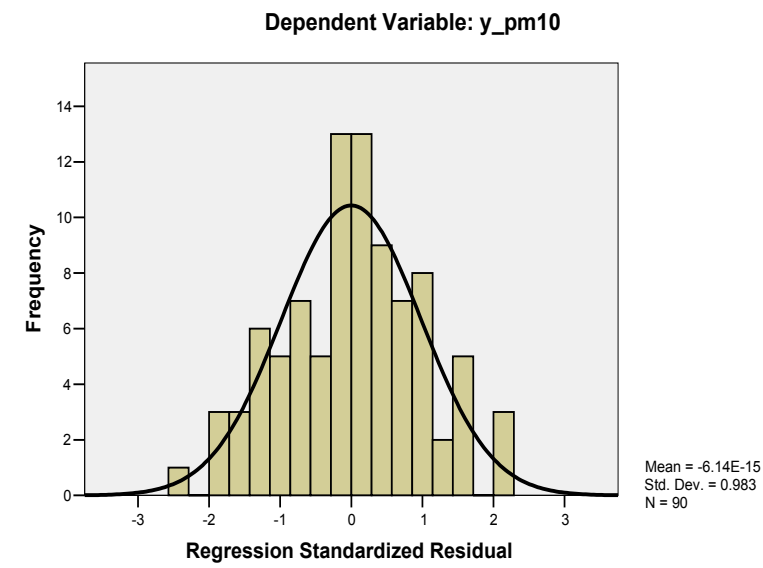

Fig. 2. Normality test

From Table V, the best regression model M11.2.1 is given by the equation (2):

$\hat{Y}=-18.0713+0.01916 X 12+0.955547 X 13-0.19387 X 23$

The interaction variables (X12 and X13) have direct positive relationships while X23 has direct negative relationship with Y. Substituting back the defined variables into equation (2), the model then becomes:

$$
\begin{aligned}
& P M 10=-18.0713+0.01916(\text { Temp })(U V) \\
& +0.955547(\text { Temp })(\text { Wind })-0.19387(U V)(\text { Wind })
\end{aligned}
$$

Table VIII shows the comparisons of best models from stations Kajang (S1), Shah Alam (S2) and Kota Bharu (S3) respectively. It can be seen from Table VIII that the best regression model with the least SSE is model M11.2.1 from Station Kajang (S1). 
TABLE VII: COMPARISONS OF SELECTED MODELS ACCORDING TO STATIONS

\begin{tabular}{|c|c|c|c|c|c|c|c|c|c|}
\hline & \multicolumn{9}{|c|}{ SELECTED MODEL } \\
\hline & Stations: & \multicolumn{2}{|c|}{ Kajang (S1) } & \multicolumn{3}{|c|}{ Shah Alam (S2) } & \multicolumn{3}{|c|}{ Kota Bharu (S3) } \\
\hline $\mathrm{N}$ & Model & $\mathrm{K}+1$ & SSE & Model & $\mathrm{K}+1$ & SSE & Model & $\mathrm{K}+1$ & SSE \\
\hline 9 & M4.0.0 & 3 & 11012.23 & M1.0.0 & 2 & 15288.87 & M2.0.0 & 2 & 13776.5 \\
\hline 9 & M5.0.0 & 3 & 11758.79 & M4.0.1 & 3 & 14746.45 & & & \\
\hline 9 & M8.1.0 & 3 & 11009.76 & M5.0.0 & 3 & 13186.66 & & & \\
\hline 9 & M9.1.0 & 3 & 11789.47 & M6.0.1 & 3 & 15011.47 & & & \\
\hline 9 & M10.0.0 & 3 & 11120.54 & M8.1.1 & 3 & 14777.79 & & & \\
\hline 9 & M11.2.1 & 4 & 9351.375 & M9.1.0 & 3 & 13258.4 & & & \\
\hline 9 & M12.3.0 & 5 & 9776.357 & M10.0.2 & 2 & 15030.17 & & & \\
\hline
\end{tabular}

TABLE VIII: COMPARISONS OF REGRESSION MODELS ACCORDING TO STATIONS BASED ON THE 8SC

\begin{tabular}{|c|c|c|c|c|c|c|c|c|c|c|c|c|}
\hline Station & MODEL & $\mathrm{K}+1$ & $\mathrm{~N}$ & SSE & AIC & FPE & GCV & HQ & RICE & SCHWARZ & SGMASQ & SHIBATA \\
\hline Shah Alam & M5.0.0 & 3 & $\begin{array}{l}9 \\
0\end{array}$ & 13186.66 & 156.619 & 156.623 & 156.797 & 161.9715 & 156.98 & 156.319 & 151.571 & 156.286 \\
\hline Kajang & M11.2.1 & 4 & $\begin{array}{l}9 \\
0\end{array}$ & 9351.375 & 113.56 & 113.569 & 113.794 & 118.7667 & 114.041 & 113.462 & 108.737 & 113.140 \\
\hline Kota Bharu & M2.0.0 & 2 & $\begin{array}{l}9 \\
0 \\
\end{array}$ & 13776.5 & 160.029 & 160.03 & 160.109 & 163.6542 & 160.192 & 162.906 & 156.551 & 159.875 \\
\hline & \multicolumn{3}{|c|}{ MIN VALUE } & 9351.375 & 113.56 & 113.569 & 113.794 & 118.7667 & 114.041 & 113.462 & 108.737 & 113.140 \\
\hline
\end{tabular}

This paper is the first that we are aware of to document the meteorological interactions (Temperature and UV; Temperature and Windspeed; UV and windspeed), interact each other to predict the $\mathrm{PM}_{10}$ concentrations. Certain combinations of Temperature and UV; Temperature and Windspeed; UV and Windspeed, might produce unique effect beyond exposure to one of these meteorological factors alone. From the model M11.2.1 obtained, shows that high Temperature with high UV, associated with high Temperature with stronger Wind will result to $\mathrm{PM}_{10}$ concentrations increase. On the other hand, decreased of $\mathrm{PM}_{10}$ concentrations are associated with high UV with strong Wind. Overall, it can be concluded that $\mathrm{PM}_{10}$ has a reverse relationship with wind speed and ultraviolet radiation, but a positive relationship with the ambient temperature. High temperature in the tropical climate usually increases the quantity of biomass burning and the evaporation of materials, for example soil dust, from the surface earth [23], [24]. In contrast to temperature, wind speed showed a negative influence on the concentration of $\mathrm{PM}_{10}$, which means that the concentration of $\mathrm{PM}_{10}$ tends to be higher in low wind speed areas [25]. Reference [26] stated that tall building in effect and hilly regions prevent wind speeds from being sufficiently strong to be able to transport the pollution away and will affect the concentration of the air pollutants. Moreover, temperatures affect pollutant concentrations by causing variations in wind circulation and simultaneously dilute the concentration of air pollutants [27]. The study also demonstrated that UV has a negative correlation with $\mathrm{PM}_{10}$. Large particles such as dust and haze are objects that are good absorbers of UV and UV emitters [28]. The UV absorption could be affected by the presence of $\mathrm{PM}_{10}$ in the air; which will lower UV intensity caused of higher presence of the $\mathrm{PM}_{10}$ and higher absorbance by the airborne particulates [29].

\section{CONCLUSION}

The best model M11.2.1 can be used to forecast the upcoming haze weather; which is given by:

$$
\begin{aligned}
& P M 10=-18.0713+0.01916(\text { Temp })(U V) \\
& +0.955547(\text { Temp })(\text { Wind })-0.19387(U V)(\text { Wind })
\end{aligned}
$$

Hence, it can be concluded that the temperature plays the important factor for increasing the $\mathrm{PM}_{10}$ concentrations in the atmosphere; however the wind speed and UV can be the limiting factors for $\mathrm{PM}_{10}$ concentrations.

\section{REFERENCES}

[1] D. Shiga, "Biomass burning as the main source of organic aerosol particulate matter in Malaysia during haze episode," Chemosphere, vol. 55, no. 88, pp.1089-1095, 2004.

[2] T. Y. Aditama, "Impact of haze from forest fire to respiratory health: Indonesian Experience," Respirology, vol. 5, pp. 169-174, 2000.

[3] M. Shima, Y. Nitta, and M. Adachi, "Effects of air pollution on the prevalence and incidence of asthma in children," Archaeology of Environmental Health, vol. 57, pp. 529-535, 2002.

[4] J. Reeva, Understanding Motivation and Emotion, New Jersey: John-Wiley \& Sons, 2005.

[5] Y. S. Chen, P. C. Sheen, Y. K. Liu, and C. Y. Yang, "Effects of Asian dust storm events on daily mortality in Taipei, Taiwan," Environmental Resource, vol. 95, pp. 151-155, 2004.

[6] D. Gupta, P. Boffetta, V. Gaborieau, and S.K. Jindal, "Risk factors of lung cancer in Chandigarh India," Indian Journal of Medical Resources, vol. 113, pp. 142-150, 2001.

[7] M. C. Lin, H. Chiu, H. F. Yu, and T. N. Sung, "Increased risk of preterm delivery in areas with air pollution from petroleum refinery plant in Taiwan," Journal of Toxicology and Environmental Health, vol. 64, pp. 637-644, 2001.

[8] Annual Report on Malaysia Environmental Quality, Malaysia Department of Environment, 2011.

[9] K. K. Chow, and J. T. Lim, J. T, Urbanization and Eco Development with Special Reference to Kuala Lumpur, Kuala Lumpur: Penerbit University of Malaya, 1983.

[10] J. Cheang, "Haze Episode October 1991: Malaysian Meteorological Service Information Paper," 1991. 
[11] K. S. Yap, "Haze in Malaysia: Meteorological Technical Report," 1995.

[12] Y. L. Lee, and R. Sequeira, "Visibility degradation across Hong Kong: its components and their relative contributions," Atmospheric Environment vol. 34, pp. 5861-5872, 2001.

[13] Y. L. Sun, G. S. Zhuang, A. H. Tang, Y. Wang, and Z. S. An, "Chemical characteristics of $\mathrm{PM}_{2.5}$ and $\mathrm{PM}_{10}$ in haze-fog episodes in Beijing," Environmental Science Technology, vol. 40, pp. 3148-3155, 2006.

[14] Q. Y. Fu, G. S. Zhuang, J. Wang, and D. G. Street, "Mechanism of formation of the heaviest pollution episode ever recorded in the Yangtze River Delta, China," Atmospheric Environment, vol. 42, pp. 2023-2036, 2008.

[15] J. H. Seinfeld, and S. N. Pandis, Atmospheric Chemistry and Physics from Air Pollution to Climate Change, New York: John Wiley, 1998.

[16] M. Demuzere, R. M. Trigo, J. V. G. Arellano, and N. P. M. Lipzig, "The impact of weather and atmospheric circulation on $\mathrm{O}_{3}$ and $\mathrm{PM}_{10}$ levels at a rural mid-latitude site," Atmospheric Chemistry and Physics, vol. 9, no.8. pp. 2695-2715, 2009

[17] T. R. Oke, H. A. Cleugh, S. Grimmond, H. P. Schmid, and M. Roth, "Evaluation of spatially-averaged fluxes of heat, mass and momentum in the urban boundary layer," Weather Climatology, vol. 9: pp. 14-21, 1989.

[18] M. Roth, "Review of atmospheric turbulence over cities," Meteorological Society, vol. 126: pp. 941-990, 2000.

[19] J. F. Hair, W.C. Black, B. J. Babin, and R. E. Anderson, Multivariate Data Analysis, $7^{\text {th }}$ Edition. New Jersey: Prentice Hall, 2010.

[20] D. D. Wackerly, W. Mendenhall III, and R.L Scheaffer, Mathematical Statistics with Applications, 6 Edition. South Western Ohio: Thomson Learning, 2002.

[21] E. J. Pedhazur, and L. P. Schmelkin, Measurement, design and analysis: an integrated approach. Hillsdale, N.J: Erlbaum, 1991.

[22] H. J. Zainodin, A. Noraini, and S. J. Yap, "An alternative multicollinearity approach in solving multiple regression problem," Trends in Applied Sciences Research, vol. 6, no.11, pp. 1241-1255, 2011.

[23] S. Z. Azmi, M. T. Latif, A. S. Ismail, L. Juneng, and A. A. Jemain, "Trend and status of air quality at three different monitoring stations in the Klang Valley, Malaysia," Air Quality and Atmospheric Health, vol. 3 , no.1, pp. 53-64, 2010 .

[24] L. Juneng, M. T. Latif, F. T. Tangang, and H. Mansor, "Spatio-temporal characteristics of $\mathrm{PM}_{10}$ concentration across Malaysia," Atmospheric Environment, vol. 43, no. 30, pp. 4584-4594, 2009.

[25] A. Donnelly, B. Misstear, and B. Broderick, "Application of nonparametric regression methods to study the relationship between $\mathrm{NO}_{2}$ concentrations and local wind direction and speed at background sites," Science Total Environment, vol. 409, no. 6, pp. 1134-1144, 2011.

[26] M. B. Celik, and I. Kadi, "The relation between meteorological factors and pollutants concentrations in Karabak City," Gazi University Journal of Science, vol. 20, no. 4, pp. 87-95, 2007.

[27] T. Banerjee, S. B. Singh, and R. K. Srivastava, "Development and performance evaluation of statistical models correlationg air pollutants and meteorological variables at Pantnagar India," Atmospheric Resource, vol. 99, pp. 505-517, 2011

[28] L. Tarbucks, The Atmosphere, $12^{\text {th }}$ Edition. Gllenview Illinois: Pearson Education Inc., 2013.

[29] A. Namdeo, and M.C Bell, "Characteristics and health implications of fine and coarse particulates at roadside, urban background and rural sites in UK," Environmental International, vol. 31, no. 4, pp. 565-573, 2005.

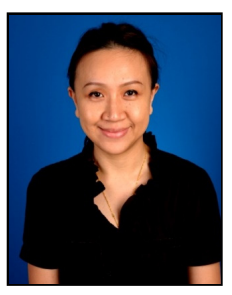

Carolyn Payus is a lecturer in Universiti Malaysia Sabah (UMS) for Environmental Science Program from School of Science \& Technology since year 2005. She specializes in atmospheric chemistry and environmental law. She is currently a PhD Scholar at Universiti Kebangsaan Malaysia (UKM), on Atmospheric Chemistry and Air Pollution.

Her research interests mainly on environmental assessment (particularly on air, biological \& water resources), environmental restoration \& rehabilitation, advanced environmental modeling, and environment \& public health. She was attached with Stellenbosch University Cape Town, National Taiwan University (NTU) Taipei, St. Andrews University Scotland and University of Belfast in United Kingdom, as research fellow in water resources and climate change expertise. She has published and presented various scientific papers (journal, conference paper, etc.) in national and international platform. She is expert member of Water Research Unit, Natural Disaster Unit and Climate Change Research Group in UMS, and also member in International Society for Environmental Information Sciences, IEEE Society and Consultant Expert for the Malaysian Environmental Protection Department.

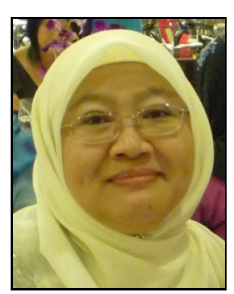

Noraini Abdullah is a senior lecturer in the Mathematics and Economics Program in the School of Science \& Technology, Universiti Malaysia Sabah (UMS). She obtained her Bachelor of Science degree from Universiti Kebangsaan Malaysia (1999), Master of Science in Industrial Mathematical Modeling from Loughborough University of Technology (2003) and finishing her doctorate in Universiti Malaysia Sabah (UMS).

Her main research projects were Modeling of the Insects Population Dynamics for the Fisheries Industries (2009), Study of Community's Communication Strategies and Modeling of the Community Transformation (2010), Consumer-Centric Study on the Usage Pattern of Television-Receive-Only (TVRO) in Sabah (2011), and The Broadband Impact in Sabah (2012). Her current research interest would include statistical modeling of the environmental factors, water quality and medical sciences.

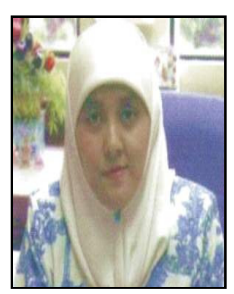

Norela Sulaiman is an associate professor from Universiti Kebangsaan Malaysia (UKM). She received her first degree, BSc in 1987 and Master degree, MSc, 1993 from Universiti Kebangsaan Malaysia (UKM) in Zoology. Her $\mathrm{PhD}$ was also from Universiti Kebangsaan Malaysia (UKM) obtained on 2002 in Air Pollution.

Her expertise is in air pollution, zoology and life cycle assessment at production system for environment. She always invited as a keynote speaker in local and international conference, as well as an environmental consultant for local and international project. She has published various journal articles, chapter in books and proceedings in her career. She is the research member for Atmospheric Chemistry and Air Pollution Research Group in UKM, Head of Student Development Committee, and previously was the coordinator of postgraduate program in School of Environmental and Natural Resources Science, UKM. 